\title{
La evolución de un cargo: \\ la Protectoría de Indios en el virreinato peruano ${ }^{1}$
}

Javier Iván Saravia Salazar

Universidad Nacional Mayor de San Marcos

javier82_ht@hotmail.com

\section{RESUMEN}

El presente artículo examina el rol del protector de indios en el virreinato peruano, desde su aparición, a mediados del siglo XVI, hasta su inclusión oficial en la Real Audiencia de Lima, en el siglo XVIII. Se propone un análisis político de los cambios experimentados por la Protectoría, considerando a esta como un espacio en donde podía ejercerse «poder». La Protectoría era, además, un espacio de interacción entre diversos actores sociales del virreinato (la Corona española, la Iglesia católica, clérigos, corregidores, protectores, curacas y caciques, autoridades locales, e inclusive el propio virrey), a través de la cual podían ejercer presiones y satisfacer intereses muy concretos.

\section{PALABRAS CLAVE}

Virreinato, siglos XVI-XVIII, protector de indios, poder.

\section{ABSTRACT}

This article examines the role of the protector de indios in the Peruvian Viceroyalty, since his creation, in the middle of XVI century, until his official inclusion in the Real Audiencia of Lima, in the XVIIII century. We propose a political analysis of the changes experimented in the Protectoría, considering it as a space where "power» could be exercised. The protectoria was a space of interaction among different social actors of the Viceroralty (the Spanish Monarchy, the Catholic Church, clergymen, corregidores,

1 Este artículo se basa en mi tesis de licenciatura en Historia: «Los miserables y el protector. Evolución de la Protectoría de Indios en el virreinato peruano. Siglos XVI-XVIII», Universidad Nacional Mayor de San Marcos, 2012. 
protectores, curacas y caciques, local authorities and even the own viceroy) through they can exercise pressure and satisfies concrete interests.

\section{KEYWORDS}

Viceroyalty, XVI-XVIII centuries, Protector de Indios, power.

\section{Introducción}

El cargo de protector de indios ${ }^{2}$ aparece por primera vez en 1516, a iniciativa del cardenal Francisco Jiménez de Cisneros, y recayó en la persona de fray Bartolomé de las Casas (1474-1566). Su creación se da en un contexto de reforma del gobierno en las Indias ante la crueldad con que se desarrollaba el proceso de colonización y «evangelización» en suelo centroamericano. La disminución alarmante de la población nativa, así como el dominio absoluto que en la práctica ostentaban los conquistadores españoles, preocuparon a la Corona y a la Iglesia, que no veían con buenos ojos la consolidación de un poder independiente en las Indias. Es así que para salvaguardar los derechos de la población aborigen se creó la figura de un magistrado encargado exclusivamente de velar por su protección y de reivindicar sus derechos ante las instancias judiciales (corregidor, Audiencia), autoridades locales (virrey), y, de ser necesario, ante el mismo rey.

Carmen Ruigómez define al protector de indios como:

un cargo burocrático más dentro del esquema de la administración indiana, pero con una atribución específica: tratar de que el indio viviera lo mejor posible dentro del marco de la legislación, evitando a toda costa las extorsiones que podrían venirle por parte de los peninsulares (Ruigómez 1988: 29).

2 Sobre el protector de indios en el virreinato peruano pueden consultarse el estudio pionero de Bayle, Constantino (1945). El protector de indios. Sevilla: Consejo Superior de Investigaciones Científicas; de Ruigómez, Carmen (1988). Una política indigenista de los Habsburgo: el protector de indios en el Perú. Madrid: Ediciones de Cultura Hispánica; de Lavallé, Bernard (1990). «Presión colonial y reivindicación indígena en Cajamarca (1785-1820), según el archivo del protector de naturales». En Allpanchis, año XII, nro. 35-36, pp. 105-137; de Óscar Acebedo, Edberto (1991). «El protector de Indios en el Alto Perú (hacia fines del régimen español)». En IX Congreso del Instituto Internacional del Derecho Indiano. Madrid: Editorial de la Universidad Complutense, pp. 29-54; de Chassin, Joëlle (1992). «Protecteur d'Indiens contre Vice-Roi: la lutte de Miguel de Eyzaguirre pour l'abolition du tribut au Pérou». En Cahiers des Amériques Latines, nro. 13, pp. 61-74; de Puente Brunke, José de la (2005). «Notas sobre la Audiencia de Lima y la protección de los naturales (siglo XVII)». En Scarleth O’Phelan Godoy y Carmen Salazar Soler. Passeurs, mediadores y agentes de la primera globalización en le Perú, pp. 231-248; en León Fernández, Dino (2005). «Un manuscrito sobre el protector de los naturales en la provincia de Collaguas. Siglo XVIII». En Revista de Investigaciones Históricas Uku Pacha, año 4, nro. 5, pp. 91-107; y de Novoa, Mauricio (2003). Defensoría del Pueblo: Aproximaciones a una institución constitucional. Lima: Universidad de Lima. 
Ernesto García Hernán precisa que el protector de indios no era propiamente un oficio, sino que estaba considerado sobre todo como un «ministerio», un servicio a los indios, pagado por los propios indios (García Hernán, 2007).

La Protectoría de Indios experimentó cambios en su estructura interna, sus funciones y en la calidad de las personas que ocuparon este cargo durante sus casi tres siglos de vida. Estos cambios eran producto de una constante pugna de intereses entre la Corona española y la élite india$\mathrm{na}^{3}$ e indígena. En un primer momento, a mediados del siglo XVI, el cargo estuvo ligado al proceso evangelizador y se constituyó como un medio de supervisión de la labor de conquistadores y colonos. Con la llegada de Francisco de Toledo, el cargo se reorganizó en función de optimizar la administración, organizando la fuerza de trabajo indígena y concentrando (en la práctica, despojando) los recursos naturales de las comunidades nativas. Toledo redefinió a la Protectoría creando el cargo de protector general de indios y un sistema de protectores de partido en las ciudades y poblados para aglutinar los reclamos indígenas, buscando así impedirles el acceso a la Real Audiencia. De este modo, pretendía desincentivar la asesoría legal privada que letrados criollos y peninsulares ofrecían a los curacas y sus comunidades. Muy a su pesar, lo que originó fue dinamizar la llamada «litigiosidad indígena» (Pease 1990, Honores 1993), pues proveyó a los indígenas de un sistema de asesoría legal oficial, con el que posibilitó la interacción entre indios y protectores, y según el cual el éxito o fracaso de sus demandas dependía de la capacidad de estos actores para entablar alianzas y estrategias. Como bien apunta Pedro Pérez Herrero, para las sociedades de Antiguo Régimen: «Las relaciones eran personales antes que institucionales» (Pérez Herrero 2002: 132).

Para el siglo XVII, se suscitó un cambio interesante en la Protectoría, a raíz de que se presentó en el Consejo de Indias la propuesta de otorgarle la dignidad de fiscal, que lo equiparaba con un oidor con asiento en la Real Audiencia. Dicha propuesta fue impulsada por miembros de la élite indiana que buscaban afianzar y extender sus espacios de influencia en la

\footnotetext{
3 Utilizo el término élite indiana para referirme a los criollos y peninsulares que ocuparon o tenían la capacidad material para ocupar cargos en la administración pública virreinal. Partiendo del concepto de elite estratégica de Suzanne Keller (1971), empleamos dos términos: élite indiana y élite indígena. En el primer grupo hacemos una subdivisión entre élite criolla y española (o peninsular). Nos referimos a élite indiana como aquella minoría de criollos y peninsulares que puede acceder al servicio político-administrativo en el virreinato y que ejerce desde fuera de la administración pública algún tipo de presión política por disponer de otro tipo de «fuente de poder» (Mann 1991). En el segundo grupo nos referimos a los curacas y demás autoridades civiles indígenas.
} 
política virreinal ${ }^{4}$. La gestación y consecución de ello representó un triunfo para los intereses criollos. Ello fue posible gracias a las redes de alianzas que la élite criolla había logrado establecer en los principales organismos administrativos del virreinato peruano (Cabildo, Real Audiencia, Consejo de Indias) y la receptividad del rey conde-duque de Olivares de atender las propuestas de gobierno de los diferentes estamentos y dominios del imperio español, a través de la retórica del arbitrismo.

Para el siglo XVIII tenemos el cargo consolidado en la Real Audiencia. Por tal motivo, representó un espacio de ascenso para criollos aún no posicionados, así como un espacio para influir en la política local. La venta de cargos, si bien fue una constante en el virreinato, dejó ver sus consecuencias negativas con mayor nitidez en este siglo. Así tenemos para el caso del protector de indios que el cargo había sido desnaturalizado y era controlado por terratenientes, que, valiéndose de su ayuda, anexaban tierras de comunidad y pequeñas parcelas de la población sin ningún tipo de sanción.

\section{Evolución de la Protectoría de Indios en el virreinato peruano}

En la historia de la Protectoría de Indios tradicionalmente se han señalado dos etapas bien marcadas: una eclesiástica y una laica (Bayle 1945, Lohmann 1957 [1994], Olmedo 1990, Ruigómez 1998). Sin ánimo de cuestionar esta periodificación, hemos optado por identificar sus procesos de cambio en función del contexto en que sus funcionarios ejercieron el cargo, a las facultades que la normativa les permitía y a la realidad material del cargo en un periodo específico, con el fin de notar los aspectos políticos y legales que esta institución presentó del siglo XVI al XVIII.

El concepto de poder que empleamos a lo largo de esta exposición es el propuesto por el sociólogo Michael Mann, en su sentido más general. Para este autor poder es: «la capacidad para perseguir y alcanzar el dominio del medio en el que habita uno» (Mann 1991: 21). A nuestro entender, la Protectoría constituye un espacio en donde pueden conseguirse intereses muy concretos: la consecución de justicia por parte de los indígenas en el primer plano, por los indios del común y las comunidades de indígenas. Pero, además de ello, confluyen en esta institución los propios intereses de los protectores, de los curacas, de otras autoridades civiles y representantes de los sectores productivos de la economía virreinal. Para

4 Sobre el particular nos hemos referido en «El fiscal protector de indios en la Audiencia de Lima siglo XVII. Espacios de poder y arbitrismo». En Actas del Quinto Congreso Nacional de Historia 2012. En http://sociales.unmsm.edu.pe/ftp/nuevacoronica/VCNH.\%20Saravia\%20 Salazar.pdf. También pueden consultarse: Cuena 1998b y 1998c, Novoa 2003 y Suárez 1995, citados en la bibliografía. 
los protectores el cargo es funcional respecto a sus intereses profesionales, pero también les es funcional a fin de entablar alianzas para conseguir ser un medio de presión en la política virreinal

\section{Los protectores y la conquista}

A partir de 1531 se invistió automáticamente a los obispos como protectores de indios. El rey otorgó al episcopado la misión de la defensa, protección y conversión de los indios. Se les nombraba como tales en la misma cédula de designación episcopal o en otra adjunta. De esta manera, la Protectoría se convirtió en una misión anexa al fuero eclesiástico contra los excesos cometidos contra los indígenas, tanto en tiempo de guerra como de paz. Se pretendió, al otorgar a los obispos la Protectoría, que su acción fuera más efectiva en provecho de los naturales (Ruigómez 1988: 57-58).

En el virreinato peruano el cargo de protector de indios estuvo ausente a la llegada de la hueste perulera, pese a que el cargo ya funcionaba en tierras mayas y disponía de amplias facultades. Posiblemente esta omisión se debió a las constantes fricciones suscitadas entre protectores obispos y conquistadores. Las reales cédulas de 1526 y 1528 que, en lo formal, protegían a los naturales estuvieron ausentes del paquete de poderes y disposiciones que Francisco Pizarro traía consigo cuando emprendió viaje a América en 1530. Por ello, ni siquiera alcanzó a tomar a bordo a los funcionarios reales. Los funcionarios que se unirían a él en 1532 tampoco llevaban los documentos referidos. Solo en mayo de 1534 la Corona se dio cuenta de que aquellos documentos nunca habían sido transmitidos a las autoridades de las provincias de «Tumbez»y «Pirú» ${ }^{5}$.

Antoni Macierewicz sostiene que la falta de aquellas cédulas reales se produjo a consecuencia de una acción consciente relacionada con las disputas acerca de la política colonial. La cédula de 1526 no precisaba prerrogativas y contenía recomendaciones muy generales de cuidar del bien, la libertad y la cristianización de los naturales. Tan solo en 1528, a raíz de los reclamos de Zumárraga, obispo de México, este documento fue provisto de actos ejecutivos que precisaban las competencias del protector de indios. Sin embargo, el documento expedido a Hernando de Luque careció de aquellas cláusulas y abarcaba solamente cuestiones de carácter muy general. Además de ello, los firmantes del nombramiento fueron la reina y el conde de Osorno, García Fernández Manrique, quien estaba relacionado con varios conquistadores ${ }^{6}$. El emperador y el presidente del Consejo

\footnotetext{
5 Porras Barrenechea, Raúl (1944). Cedulario del Perú. Lima: Departamento de Relaciones Culturales del Ministerio de Relaciones Exteriores del Peru, tomo I, pp. 20-21.

6 Ibíd., p. 132.
} 
de Indias fray, García Loayza, se encontraban en Barcelona (Macierewicz 1989: 117-118).

Hernando de Luque, el socio «capitalista» de Pizarro y Almagro en la empresa de la conquista, fue nombrado como protector el 26 de julio de 1529. En la Capitulación de Toledo se pidió para él el Obispado de Tumbes y, mientras se le despachaban las cedulas, se le dio el nombramiento de protector de los indios. Pero Hernando de Luque se retrasó en ir a su nuevo territorio, por lo que en su lugar se nombró a fray Reginaldo de Pedraza, prior de los frailes de la Orden de Santo Domingo, como protector de indios, por Real Cedula del 4 de abril de 1531.

Desde que se destituyó del cargo a Hernando de Luque (4 de abril de 1532), quien ejerció este cargo (en el papel, ya que nunca llegó a pisar territorio peruano) fue fray Reginaldo de Pedraza. Su nombramiento, expedido en Ocaña, es una copia literal del de Hernando de Luque, excepto en un punto ${ }^{7}$. Al final de la cedula se le brindan unas instrucciones, que De Luque no había tenido. Estas, por una parte, clarifican su misión; por otra, aunque parezca paradójico, la limitan bastante, siempre dentro de cierta ambigüedad. Leuridan Huys ha destacado las siguientes:

a) se autoriza al protector, cuando no pueda visitar personalmente a los indios de la Gobernación, a enviar visitadores en su lugar, pero con la condición de que tales personas sean vistas y aprobadas por el gobernador y oficiales y de otra manera ninguna persona puede ir a visitar.

b) se permite al protector y a los visitadores por él nombrados hacer solo pesquisas e informaciones referentes al trato a que se somete a los indios [...]. El protector y sus visitadores solo pueden aplicar penas pecuniarias de 50 pesos para abajo o menores de 10 días de cárcel.

c) se permite hacer informaciones aun contra el gobernador y sus oficiales, con el fin de enviarlas al Consejo de Indias, pero se advierte expresamente que por esto no es su intención ni voluntad que los protectores tengan superioridad alguna sobre las dichas nuestras justicias.

d) se establece que los pleitos entre los mismos indios pertenecen a la jurisdicción del gobernador y no a la del protector [las cursivas y negritas son nuestras] (Leuridan 1997: 24-25).

Estas instrucciones se van a repetir a partir de esta fecha en las cédulas de los religiosos designados como protectores.

7 El texto completo del nombramiento de Pedraza puede consultarse en Ruigómez 1988: 184-186. 
Para 1532 ya eran conocidos por los conquistadores el establecimiento del oficio de protector de indios; la real cédula de 2 de mayo de 1530 prohibía esclavizar a los naturales incluso en guerra justa, comerciar con esclavos y recibirlos de los gobernantes indios. Estas decisiones fueron notificadas por los funcionarios reales que se unieron a la hueste perulera en la isla de Puna, a mediados de 1542. Además, llegaron notificando que Pizarro no había recibido autorización de repartir encomiendas, sino tan solo promesa de otorgársela en el futuro. Todo ello causó un bullicio en el campamento, que trajo consigo una abierta disputa entre el tesorero Riquelme y Hernando Pizarro, con claros indicios de estallar una rebelión abierta (Macierewicz 1989: 119). Esta peligrosa situación fue superada por la casi inmediata repartición del botín recogido hasta ese momento. Fue enviado a España Rodrigo Mazuelos, quien en nombre del gobernador y los conquistadores iba a solicitar: 1) que se despache la decisión de garantizar el derecho de repartir encomiendas, 2) que se suprimiese la prohibición de recibir esclavos y comerciar con ellos, y 3) que se reestableciese la ley de convertir en esclavos a los naturales hechos esclavos en guerra justa. En marzo de 1533 el conde Osorno aceptó los reclamos de Mazuelos (Macierewicz 1989).

Antes de que fray Vicente de Valverde fuera nombrado protector de indios (1538), le antecedió Gabriel de Rojas (153?), nombrado por Francisco Pizarro, ya como gobernador, quien le otorgó el cargo en agradecimiento por su brillante actuación en la batalla de las Salinas (Ruigómez 1988: 56).

Sobre el particular sabemos que:

Al capitán Gabriel de Rojas le hizo merced el marqués de que protector general de los indios del Cusco y sus términos por lo bien que lo hizo en la batalla de las Salinas. Y porque su majestad le había dado título de protector general de los indios de todo el Perú al obispo P. Fr. Vicente de Valverde, por cédula dada en Valladolid á 14 de julio de este año, con poder de visitar las partes donde están encomendados ver cómo los tratan porque no se acaben como en las islas Barlovento; aunque presentó este título en el Cabildo del Cusco, á 22 de diciembre de este año [de 1538] se suspendió obedecer la real cédula por el marqués, hasta tener que dar al capitán Gabriel de Rojas (Montesinos 1906, Torres 1932).

\section{El informe de Fray Tomás de Berlanga}

Poco después de iniciada la conquista y mucho antes del establecimiento de la capital española en Lima, o de la toma de posesión de la primera sede eclesiástica, la Corona decidió, con buen tino, poner en marcha lo que puede considerarse la «primera visita oficial» efectuada al gobernador Pizarro y a los funcionarios de la Real Hacienda. Para dicho fin se 
nombró a fray Tomás de Berlanga ${ }^{8}$, obispo de Tierra Firme, para que señalara la jurisdicción de los encomenderos y tasaran los tributos que pagarían a estos ${ }^{9}$ (Málaga 1993: 268). Su estadía en Lima se extendió desde el 20 de agosto hasta el 13 de noviembre de 1535, tiempo en que se efectuó su llamado «informe secreto».

En sus instrucciones de 1534, con referencia a los pueblos de indios se señalaba lo siguiente:

Asy mesmo os ynformad que poblaciones de yndiso hay en dha tierra, y que manera tienen en su población y governación y policía y que ritos y costumbres y que artes de cajes y como tratan sus familiares y de que viven y de su manera de granjerías y sí son ricos y que manera de haziendas tienen y de sus ritos, crimonias y crehencias y de su capacidad y que heredado con las que tienen (2v) que cosas han ocupado hasta aquí y se deben ocupar adelante para vivir en pulicía según su habilidad ${ }^{10}$ (Málaga 1993: 268).

Las condiciones del proceso de conquista y la subsiguiente guerra civil entre Francisco Pizarro y Diego de Almagro contribuyeron a afianzar una alianza entre el clero y la Corona para frenar a los conquistadores. Berlanga, entre otras cosas, fue comisionado con amplias facultades para limitar el poder de los conquistadores e incluso privárselos. Dentro de sus muchas observaciones, Berlanga incidió mucho en la irregularidad de los repartimientos efectuados por Pizarro; se acusaba al gobernador de no haber reservado suficientes tributarios. A lo largo de su estadía en suelo americano, Berlanga testimoniará la animadversión de Pizarro hacia él y sus intentos de soborno y amedrentación (Macierewicz 1998 y Varón Gabai 1992).

8 Fray Tomás de Berlanga había recibido el nombramiento del decaído obispado de Tierra Firme, con sede en Panamá. Aprovechando su viaje, la Corona consideró oportuno encargarle la elaboración de una detallada «Información del Perú», que tendría como finalidad evaluar los numerosos problemas que se habían suscitado entre los españoles. Por tal motivo, en Valladolid, el 19 de junio de 1534, Carlos V firmó las cartas, provisiones e instrucciones que le serían necesarias al prelado para cumplir su misión. Quedaba claro, en opinión de Varón Gabai, que Berlanga debía tomar posesión de su sede y pasar al Perú en persona y sin pérdida de tiempo, dada la urgencia de las circunstancias. Simultáneamente se emitieron comunicaciones para Pizarro y los oficiales reales del Perú, haciéndoles saber el nombramiento y ordenándoles prestarle todo el apoyo necesario para el buen cumplimiento de su misión, como queda testimoniado en las cartas recopiladas por Porras Barrenechea, op. cit., tomo II, pp. 177-195, y Varón Gabai 1992: 118-119, nota 25).

9 Torres Saldamando, Enrique. Libro primero de Cabildos de Lima, tomo II, pp. 96 y ss.

10 Instrucciones dadas a Fray Tomás de Berlanga, Valladolid, 19 de julio de 1534, AGl, Audiencia de Lima, Leg. 565, libro 2, folios del 1-5. También existen instrucciones similares para Reginaldo de Pedraza en Instrucciones para la protección de los naturales del Perú, otorgadas a fray Reginaldo de Pedraza, Ocaña, 4 de abril de 1531. AGI, Lima 565, libro I, folio 91 y ss. El documento puede ser consultado íntegramente en Ruigómez 1988: 184-186, documento 3. 
La presencia de religiosos desde las primeras expediciones de conquista y a lo largo del proceso colonizador obedecía a la necesidad de proveer de un sustento ideológico, pero además de ello los religiosos se constituyeron en informantes y fiscalizadores a favor de la Corona ${ }^{11}$. Después de su estadía (1534-1536) se nombrará a Vicente de Valverde como protector de naturales, y se le dotó de amplias facultades y prerrogativas. La apreciación de James Lockhart resulta esclarecedora al afirmar que: «el Consejo de Indias esperó encontrar en Valverde un brazo independiente que controlase a los Pizarro, además de convertirlo en una fuente de información alternativa al mismo Pizarro» (Lockhart 1979: 204; Varón Gabai 1992: 117). Ante la ausencia de funcionarios de la Corona en suelo americano, se valieron para monitorear a los díscolos conquistadores de representantes del ente más organizado de la época: la Iglesia católica.

Los representantes de la llamada etapa eclesiástica de la Protectoría fueron: fray Vicente de Valverde (1536), fray Jerónimo de Loayza (1543) y fray Juan Solano (1546). De Valverde se dispone de documentación sobre dos sentencias emitidas como protector de naturales y ha quedado debidamente testimoniada su disputa con conquistadores y encomenderos en el ejercicio de sus funciones como protector de naturales. La documentación sobre Loayza y Solano es más esquiva; no obstante ello, existe información sobre su participación y vinculación con los demás estamentos de la Corona (encomenderos, curas doctrineros) y sus posiciones políticoadministrativas ${ }^{12}$.

Durante los años 1532 a 1550, los encomenderos fueron los que tuvieron mayor participación en la repartición de las ganancias de la empresa conquistadora y la implantación de la administración virreinal. Gozaron del usufructo ilimitado de las riquezas del Nuevo Mundo. La economía encomendera marcará la pauta de la política en Indias; debido a ello, la

11 Horst Piteschmann nos dice que durante la epata de colonización de los territorios, las órdenes religiosas, que aportaron casi la totalidad del clero en los primeros momentos de la conquista, se convirtieron en el aliado natural de la Corona en sus enfrentamiento a los encomenderos. Por un lado, las órdenes precisaban de un alto grado de autoridad para llevar a cabo con éxito su labor evangelizadora, para lo cual se encontraban en una desagradable relación de dependencia con los encomenderos. Por otro, las órdenes y los encomenderos se encontraban compitiendo por la fuerza de trabajo indígena. Esta alianza inicial entre las órdenes religiosas y la Corona, dentro del marco del patronato real, permitió que el Estado colonial emplease a los sacerdotes como fiscalizadores de las expediciones de conquista, y luego de los gobiernos embrionarios surgidos de estos (Piteschmann 1989: 108-109 y Varón Gabai 1992: 111).

12 Jerónimo de Loayza fue encomendero y Juan Solano manifestó abiertamente la inconveniencia de la aplicación de las Leyes Nuevas que eliminaban a la encomienda. Las disputas entre Loayza, obispo de Lima, y Solano, obispo de Cusco, fueron un reflejo de la pugna por la preeminencia de sus respectivas diócesis, que terminó con la renuncia del segundo a su diócesis y opacó la labor de protección de los naturales de ambos obispos, pues el tema central de sus preocupaciones fue el cobro del diezmo en sus respectivas diócesis. 
Protectoría de Indios fue inoperante no solo por la ambigua y poco clara legislación sobre las competencias, facultades y jurisdicción de los protectores de indios, sino porque, además, los que desempeñaban esta función estaban involucrados activamente en la economía encomendera y la institución misma estaba sustentada en ella. La supervivencia de la institución dependía en buena cuenta que los protectores obispos ampliaran su influencia, la Protectoría y la defensa de los indios era el medio disponible para conseguir dicho fin. En última instancia, lo que se discutía en las constantes enfrentamientos jurisdiccionales entre obispos y autoridades civiles era el espacio de poder que la Iglesia y sus representantes ocupaban en el Virreinato.

\section{La Audiencia y los fiscales}

A partir de la década de 1560, los obispos fueron relevados de la Protectoría. La defensa de los indígenas pasaría a recaer bajo responsabilidad de los fiscales de la Audiencia. Para el caso peruano, ocurrió desde 1554 (1557, según Solórzano). En este proceso se presentan los primeros comentarios negativos sobre la tendencia litigiosa de los indígenas. Pero esto no es de extrañar, debido a que existía una constante pugna entre los estamentos privilegiados del virreinato (clero, autoridades locales, encomenderos) por la apropiación de la mano de obra y recursos de los indígenas, la apertura del sistema jurídico, y principalmente por el proceso de composición de tierras. Los comentarios negativos de este cambio resonaron en todas las audiencias del Imperio español en Indias.

Para 1550 los juicios de los caciques (y/o curacas) inundaban la Audiencia de Lima. En 1567, la Corona quiso detener el aumento de representantes legales, e informó al presidente y a los oidores de la Audiencia de Quito sobre «protectores de indios» pagados por ellos mismos y que causaban notables daños a sus patrocinados. De modo que para evitar que esta situación se prolongara, y en vista de «muchas causas y razones de consideración», se ordenó la eliminación y prohibición de estos letrados (Novoa 2003: 53).

\section{El protector general de indios toledano}

Con el virrey Francisco de Toledo aparecerá la figura del protector general de los indios, quien actuará a modo de procurador de los indígenas en los pleitos en que estos fuesen parte y que hubieran de ventilarse en segunda instancia ante la Real Audiencia ${ }^{13}$. Las ordenanzas sobre el

13 Para las obligaciones de dicho funcionario, consúltese: Bayle 1945, Ruigómez 1988 (capítulos V a VII), así como el nutrido cúmulo de disposiciones contenidas en la Recopilación de 1680 que le atañen. 
protector general de indios trazan las líneas maestras de lo que va a ser el cargo en el Virreinato del Perú. Son instrucciones en las que se detallan las funciones, prerrogativas, las obligaciones, derechos, etc., de los nuevos protectores ${ }^{14}$. Concebida originalmente como una institución independiente, la Protectoría se convierte, desde el momento en que los nombramientos se atribuyen a los virreyes y gobernadores, en dependientes de las autoridades provinciales.

Estas ordenanzas serán fundamentales en la historia de la Protectoría, puesto que un siglo después aparecerán en la Recopilación de las leyes de los Reinos de las Indias de 1680 sin mayores cambios:

Ley II. Que en el Perú se dan las instrucciones, conforme a las ordenanzas, del virrey don Francisco de Toledo. [...]

En los Reinos del Perú se han de dar las instrucciones a los procuradores, conforme a las ordenanzas, que hizo el virrey don Francisco de Toledo, añadiendo lo que conforme a la diferencia de los tiempos conviene al amparo y defensa de los indios ${ }^{15}$.

Se ha señalado que una dificultad para que las ordenanzas pudieran cumplir sus fines era que no exigían que el protector fuera letrado, sino - con expresión muy propia de la época- «mero laico y de capa y espada» (Suárez 1995, Cuena Boy 1998c, Novoa 2003). La intención del virrey Francisco de Toledo al establecer esta previsión fue la de liberarlo de cualquier otra ocupación que no fuera el cuidado de los naturales, pero acabó dando un protagonismo preponderante al abogado general de in$\operatorname{dios}^{16}$, de cuyo consejo dependía el protector prácticamente para todo lo relacionado con su actuación. De este modo, el abogado venía a ser el auténtico protector mientras que el nombrado para tal oficio, necesitado él mismo de un abogado o letrado. Sin embargo, el dato no es del todo cierto, pues muchos protectores generales fueron letrados.

Para el caso de la Audiencia del Lima, en el periodo posterior a las ordenanzas de Toledo tenemos información de dos protectores de indios, Baltazar de la Cruz de Azpeitia (aproximadamente desempeñó el cargo entre 1575 y 1577) y Juan Martínez Rengifo (1577-1582). Del primero solo tenemos las referencias que nos proporciona Carmen Ruigómez en su

14Ordenanzas del virrey don Francisco de Toledo relativas al defensor general de los indios, Arequipa, 10-IX-157, en Ruigómez 1988: 188-197.

15 Recopilación, libro VI, título VI, ley II [1681] 1943.

16 Este oficio tuvo su origen en el sistema de «asesoría legal pública» creado por el virrey Toledo de 1574 a 1575 (Honores 2007). Este abogado se encargaba de la asesoría jurídica de los curacas y sus comunidades en los litigios presentados ante la Real Audiencia de Lima. 
listado de protectores de indios (Ruigómez 1988: 224); sobre el segundo, en cambio, sí disponemos de mayor información ${ }^{17}$.

Con Juan Martínez Rengifo ${ }^{18}$ se hace evidente el cambio en la política en Indias, al incentivar la Corona a un tipo diferente de colono tras la derrota de los encomenderos a uno más ligado a los intereses de la Corona y con ambición de integrar el aparato burocrático del Imperio español en Indias (Rodríguez 2005). Martínez, formado en leyes al llegar a la Protectoría, representó a los verdaderos intereses de la Corona, y se encargó de la organización y administración de las tierras de indios, así como de las transacciones de tierras; trató de evitar que estas conllevaran un perjuicio para los indígenas y estaba a cargo de efectuar visitas para controlar el número de mitayos para las diferentes actividades. Desempeñó el cargo hasta su supresión en 1582.

Al reaparecer la Protectoría en la última década del $\mathrm{XVI}$, tenemos como protector de indios a Alberto de Acuña ${ }^{19}$, quien también era letrado y un importante oidor de la Audiencia de Lima (Moreyra 1957 y 1994). Por lo general, los protectores generales de indios eran letrados debido a que el cargo era de asesoría legal a los indígenas y también un cargo con algún tipo de influencia política. Son los protectores partidarios a los que no se les exigirá que sean letrados y los que habitualmente fueron denunciados por los indígenas por el incumplimiento de sus obligaciones.

\footnotetext{
17 Sobre dicho personaje puede consultarse Rodríguez Quispe, David (2005). Por un lugar en el cielo: Juan Martínez Rengifo y su legado a los jesuitas 1560-1592. Lima: Fondo Editorial de la Facultad de Ciencias Sociales de la Universidad Nacional Mayor de San Marcos.

18 Juan Martínez Rengifo nació en 1531, hijo de Alonso Muñoz Martínez Rengifo y Francisca Lozano Pinel. Además de él, la pareja tuvo tres hijas: María, Ursula y Gracia y un hijo, Diego. De María y Gracia se sabe que contrajeron nupcias con importantes miembros de la administración virreinal y cuyos matrimonios fueron supervisados por él mismo. Desde su llegada, Juan Martínez Rengifo se dedicaría a la carrera pública aprovechando sus estudios en leyes, lo cual le permitió el ingreso al Cabildo limeño a fines de 1555. Fue teniente de alguacil mayor (1566), fiscal de la Audiencia (1568), administrador general de los Censos de Indios, depositario general y protector de indios (1577-1582), y asesor del octavo virrey García Hurtado de Mendoza, marqués de Cañete.

19 Nació en Jaén, aproximadamente en 1565. Fue hijo legítimo del licenciado don Gabriel Núñez y de doña Juana de Acuña. Fue asesor del virrey conde de Villardompardo (1584) con quien pasó al Perú, oidor de la Audiencia de Panamá (1595), oidor de la Audiencia de Quito (1602), alcalde del crimen de la Audiencia de Lima (1603), oidor de la Audiencia de Lima (1607), presidente de la Audiencia de Guadalajara (1625), promoción que declinó, por lo que fue nuevamente nombrado oidor de la Audiencia de Lima (1628). Falleció el 30 de abril de 1630 (Lohmann 1974: 151-152). Guillermo Lohmann no menciona en su estudio Los ministros de la Audiencia de Lima (1700-1821) que Alberto de Acuña haya sido protector de indios. Sin embargo, las fuentes a las que se remite son los apuntes biográficos que sobre Acuña nos proporciona Manuel Moreyra Paz Soldán, quien sí señala que fue protector de indios durante la última década del siglo XVI (Moreyra 1954 y 1994).
} 


\section{El fiscal protector}

Hasta 1620 no se produjeron cambios en el cargo tras su reincorporación al ordenamiento jurídico virreinal. Continuó siendo norma básica las instrucciones del virrey Toledo. A partir de este año, a los protectores generales de los indios se les otorgó el título de fiscales protectores, de modo que se les equiparó con el fiscal civil y el crimen de las demás reales audiencias del virreinato. Esta equiparación afectó, fundamentalmente, la consideración social de los protectores. Por real cédula, y en ese mismo año, en el deseo de dar estabilidad al cargo y de garantizar alguna autonomía a sus titulares, el rey ordenó a virreyes y a gobernadores que, una vez elegidos, no los removieran ni quitaran, si no fuere con causa legítima cierta y examinada por la Real Audiencia respectiva. En 1622 por Real Cédula de 17 de marzo se trata de armonizar las relaciones entre los protectores y las autoridades provinciales. El rey encarga y manda a los virreyes y gobernadores que:

den grata audiencia á los protectores y defensores de Indios; y quando fueren a darles cuenta de sus negocios, y causas, y pidieren el cumplimiento de las leyes, y cédulas dadas a su favor, los oygan con mucha atención, y de tal forma que mediante el agrado con que les recibieren, y oyeren, se animen a su defensa y amparo (Suárez 1995: 288).

En el virreinato peruano fue a partir de 1643 cuando se instituyó en la Audiencia de Lima el cargo de fiscal protector de los indios, con carácter autónomo y como magistrado independiente, y que podía vestir toga como los demás integrantes de dicho tribunal. Su misión consistía en actuar de defensor nato de los indígenas de todo el distrito de la Audiencia, no solo en calidad de procurador de sus pleitos sustanciados ante ella, sino, sobre todo, amparándolos en caso de queja contra sus corregidores, acogiendo sus demandas para reducción del monto de los tributos, y en resolución, tendiendo su manto protector sobre los nativos para evitar toda ofensa o agravio que se pretendiere inferirles. El tema de la defensa de la propiedad agraria y los efectos de las composición de tierras determinaron, según Santiago Gerardo Suárez, que por real cédula del 30 de junio de 1646 se ordenara que en los casos en que españoles hubieran adquirido tierras de indios de modo ilícito, los fiscales protectores debían pedir en nombre de ellos la nulidad de dichas adquisiciones (Suárez 1995: 302).

Se dotó al fiscal protector de asiento en los estrados. Dentro del lenguaje forense y en la legislación indiana, la expresión estrados en plural se refiere a la sala en la que el presidente y los oidores de la Audiencia administran justicia y también el tiempo destinado a oír a los litigantes, 
juzgar las causas y dar sentencia (Bravo 1989: 255). Es muy significativo e ilustrativo que tanto Francisco de Alfaro ${ }^{20}$ como Juan de Solórzano destaquen este derecho a sentarse en los estrados concedida al fiscal como una de sus preeminencias. Al tratar del asiento que corresponde al fiscal, Solórzano contrapone el sitial de los oidores en el tribunal y el escaño de los abogados, situado en las gradas de este. Recuerda que antes los fiscales no se sentaban en el tribunal con los oidores, sino debajo de las gradas de él, en el primer lugar del escaño de los abogados ${ }^{21}$. Por ende, el hecho de que el fiscal protector haya sido equiparado a un oidor de la Audiencia lo dotaba de un gran peso político en el seno de la Audiencia.

Además, los fiscales protectores podían usar la garnacha ${ }^{22}$, vestidura propia de los oidores consistente en:

una toga talar, es decir, que llegaba hasta los talones, con mangas y una vuelta que desde los hombros caía sobre la espalda. Era de color negro y en el siglo XVII la acompañó la golilla, adorno hecho de cartón forrado en tela que rodeaba el cuello y llevaba unido por delante, en la parte superior, un pedazo que caía por debajo de la barba, con esquinas a los dos lados, sobre el cual se ponía una tela de gasa engomada o almidonada. El uso de la garnacha se reservó a los oidores y al fiscal de las Audiencias de Indias, con prohibición de que pudieran vestirla otras personas de cualquiera calidad, estado y condición por Real Cédula de 22 de mayo de 1581. Con ellos se pretendía que estos magistrados se distinguieran en el hábito de todas las demás personas, para que todo sea claro y por él sean conocidos y respetados como conviene (Bravo Lira 1989: 258).

Según el Tesoro de la lengua española, la garnacha era una vestimenta de personajes graves «Con vueltas a las espaldas y una manga de rocadero».Esta indumentaria tenía todo un simbolismo; al respecto, Juan Carlos Talavera ${ }^{23}$ nos dice que:

20 Tractatus de Officio Fiscalis, deque Fiscalibus Privilegiis. Madrid, 1780, glossa 31, 7. Citado en Bravo 1989: 257 y 263.

21 Política Indiana, libro V, capítulo 4, 13, nota 31.

22 Se trata ante todo de una expresión externa de la dignidad de estos magistrados judiciales. Así lo entendía Francisco Alfaro (Bravo Lira 1989: 259). En una Real Cédula fechada el 20 de agosto de 1620, el monarca pide al virrey de Esquilache le informe si «convendrá» que los protectores generales que residían en las ciudades donde existían audiencias fuesen letrados, y se les diera garnacha, asiento en los Estados como a los oidores (Política Indiana, libro 2, capítulo 28, nota 47, y Suárez 1995: 287).

23 Comunicación personal con el autor. Agradezco a Juan Carlos Talavera Velezmoro por sus valiosos apuntes sobre el simbolismo de la «garnacha» en la sociedad virreinal. Sobre Juan Carlos Talavera Velezmoro, consúltese la ponencia «Indumentaria académica sanmarquina: una introducción histórica sobre el antecedente y evolución del traje académico protocolar en el Perú» en el XI Coloquio de la Historia de Lima (2009). 
aparece en el siglo XIII y es considerada como parte del conjunto de ropajes de corte talar. Con el tiempo, magistrados y jueces la vistieron en el fuero jurídico. La palabra viene de guarnir, pues el vestido no solo protegía a quien lo usaba contra el frío, sino que simbolizaba la defensa y amparo, por ser vestimenta reservada a quienes representaban la ley para infundir respeto en la gente. Se atribuye al rey Felipe II el haber decidido que todos sus consejos, oidores, cancillerías y fiscales llevasen esta ropa, pero es durante el reinado de Carlos V que dicha «toga» será portada por los altos funcionarios de la administración virreinal (Talavera, 2009).

Sobre la garnacha y los estrados ha quedado un testimonio iconográfico en la crónica de Guamán Poma de Ayala, en el dibujo La Audiencia de Lima: presidente, oidores, alcaldes, que retrata claramente a siete letrados usando garnachas, por lo que podemos ver ya a esta vestimenta talar como un símbolo de poder de las altas autoridades virreinales, como lo ha hecho notar Juan Carlos Talavera (Talavera 2009).

La Audiencia de Lima: presidente, oidores, alcaldes, fiscal y alguacil mayor de este reino.

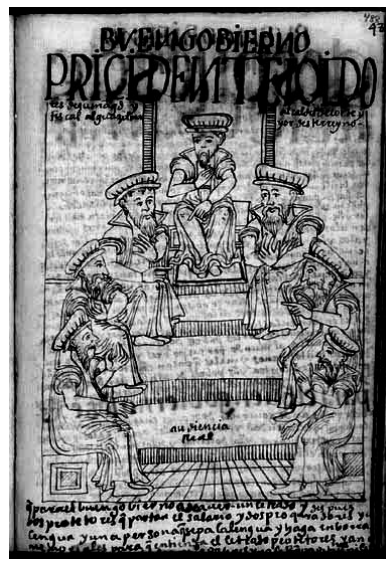

Guamán Poma de Ayala, Felipe (2001 [1615]). El primer nveva corónica i Bven Gobierno conpuesto por don Phelipe Gvaman Poma de Aiala. «Dibujo 197». Consultado el 7 de mayo de 2012 de http://www.kb.dk/permalink/2006/poma/info/es/frontpage.htm

La institución tuvo una corta vida, de 1643 a 1648 aproximadamente. Una real cédula enviada al virrey conde de Salvatierra informaba que, a pesar de las numerosas disposiciones para el buen tratamiento y alivio de los indios, todavía continuaban las molestias de parte de los gobernantes y de los habitantes en general. Esto se debía a que los protectores 
nombrados no cumplían con sus obligaciones. El incumplimiento trajo como consecuencia, mientras continuaba la cédula, la disminución del número de individuos y el desmedro de las arcas reales. La elevación a la categoría de fiscales que tuvieron los protectores solo había servido para empeorar la situación y el cargo, en virtud de la posición social que traía consigo, había sido materia de compra. Además, debido a su capacidad de representar las causas indígenas, existieron serias denuncias de sobornos en su contra (Stern 1982: 195). Se resolvió, entonces, que el oficio de protector regresara a "su antiguo instituto» y se otorgaran a personas que procedieran sin interés (real cédula de 1648 en Madrid a 28 de agosto, citado en Ruigómez 1988: 216). Esta misma cédula ordenaba la devolución de los dineros que se dieran por el cargo, pero sin que estos provinieran de la Real Hacienda.

El virrey Alba de Liste, en una real cédula de febrero de 1657, casi una década después de que se decretara el fin de los fiscales protectores, le manifestaba al rey que el conde de Salvatierra había escrito, en 1650 y en 1652, que la cantidad de dinero requerida para resarcir a aquellos que habían obtenido el oficio de protector era «considerable» y forzosamente debía provenir de la Real Hacienda, por no haber otros medios. No sabemos con certeza si la institución se mantuvo ante la incertidumbre de la devolución de los pagos. Francisco de Valenzuela, fiscal protector de la Audiencia de Lima, escribió al rey suplicándole otra magistratura, en vista del tenor de la real cédula de 1648 . El rey no emitiría la aprobación de usar los fondos de la Real Hacienda hasta 1657. El costo ya no era tan alarmante, puesto que los fiscales protectores de Lima y Quito habían muerto. Solo quedaba vivo el fiscal protector de Charcas.

En este interregno de tiempo existe información sobre Francisco de Valenzuela en el cargo de fiscal protector. Posteriormente, en 1657, se le concedió a Diego de León Pinelo el mismo título, en virtud de su prestigiosa trayectoria como jurista. Ocupó el cargo hasta su muerte, en 1671, año en que fue nombrado oidor de la Audiencia, nombramiento que no llegó a ejercer ${ }^{24}$. De él ha quedado documentación sobre los procesos judiciales llevados a favor de los indígenas y las composiciones de tierras ${ }^{25}$, además

24Sobre Diego de León Pinelo puede consultarse Pizarro Baumann, Jimena (1993). Los León Pinelo. Una familia de cristianos nuevos en el siglo XVII peruano. Tesis para optar por el grado académico de bachiller en Humanidades con mención en Historia. Lima: Pontificia Universidad Católica de Perú. En este texto se propone que la tardía llegada a la Audiencia de Diego León Pinelo, aunque cumplía desde hace mucho antes con los requisitos, fue producto de su ascendencia judía.

25 Ver al respecto Hosting, Reiner; Palomino Dongo, Ciro, y Decoster, Jean-Jacques (2002). Proceso de composición y titulación de tierras en Apurímac, Perú. Siglos XVI-XX. Tomo I. Cusco: Instituto de Investigaciones Jurídicas y Asesoramiento. 
de su famoso Memorial de 1661, en respuesta a las críticas de Juan de Padilla ${ }^{26}$. Sobre el fiscal protector de naturales, existen interesantes memoriales ${ }^{27}$ que nos aproximan a la importancia del cargo o al menos a las expectativas que depositaban en ellas los criollos desde 1620.

\section{El protector de la Recopilación de 1680}

En la Recopilación se aclaró la inconstancia que había existido en años anteriores respecto a la figura del protector de indios, al señalarse que en último término deben ser proveídos y nombrados por el virrey o los presidentes gobernadores en las provincias. La supervisión de sus actos quedaba a cargo de los jueces de visitas y residencias, así como de otras justicias ${ }^{28}$. Otras precisiones adicionales sobre el cargo fueron que debía acompañarlo un abogado y un procurador de indios, para que le asistan y sigan los procesos; debían ser asalariados y, por ello, no debían cobrar por sus servicios a sus representados ${ }^{29}$. No podían encargar sus funciones a sustitutos y debían acudir personalmente al cuidado de sus obligaciones de vigilancia.

La normativa ha sido entendida por algunos investigadores como una respuesta a los memoriales enviados por los criollos sobre el oficio de protector de indios, que denunciaban una falta de enlace e incluso displicencia de las autoridades coloniales respecto a las actividades de la Protectoría (Ruigómez 1988, Novoa 2003: 66). Sin embargo, debido a la

26 Sobre la polémica entre Juan Padilla y Diego de León Pinelo puede consultarse Torre Villar, Ernesto de la (1979). Los pareceres de don Juan de Padilla y Diego de León Pinelo acerca de la enseñanza y buen tratamiento de los indios. México D. F.: Universidad Nacional Autónoma de México. El autor hace un interesante estudio preliminar de los documentos e incluye sus transcripciones. Para un análisis de la polémica en lo referente al estado de la evangelización en el Virreinato del Perú, ver Marzal, Manuel (1988). La transformación religiosa peruana. Lima: Fondo Editorial de la Pontificia Universidad Católica del Perú, pp. 119-169. Encontramos un análisis de los aspectos políticos de esta polémica en el contexto de la visita general de 1664-1690 en Andrien, Kenneth J. (2011). Crisis y decadencia. El Virreinato del Perú en el siglo XVII. Lima: Instituto de Estudios Peruanos, pp. 134-165. Sobre el posible «discurso criollo» presente en estos memoriales, consúltese Torres Arancivia, Eduardo (2006). Corte de virreyes. El entorno del poder en el Perú en el siglo XVII. Lima: Fondo Editorial de la Pontificia Universidad Católica del Perú.

27 Podemos destacar los siguientes: Memorial al Rey N. S. Don Felipe IIII. En favor de los indios del Piru. Sobre el oficio de Protector General en la ciudad de Lima, corte y cabeza del Piru (1622), de Cristóbal Cacho de Santillana; Memorial discursivo sobre el oficio. De protector general de los indios del Piru, de Juan de la Rynaga Salazar (1626), y el Memorial histórico y jurídico, que refiere el origen del oficio de protector general de los indios del Perú en su gentilidad, causas y utilidades de su continuación, por nuestros gloriosos reyes de Castilla, nuevo lustre y autoridad que le comunicaron, haziéndole uno de sus magistrados con toga, y motivos que persuaden su conservación (1671), de Nicolás Matías del Campo y Larrinaga. Además de los mencionados, se sabe de un memorial presentando por el protector Domingo de Luna, mencionado en el folio 5 del Memorial de Matías del Campo.

28 Recopilación 6.6.1.

29 Recopilación 6.6.3. 
naturaleza del cargo en el siglo XVII, creemos que la normativa buscaba crear mecanismos de contacto real y ayuda mutua entre los funcionarios virreinales, así como subordinar el cargo a las autoridades virreinales, eliminando su influencia política, a fin de poner freno a las disputas entre la Protectoría y las demás justicias civiles. La normativa reglamentó el oficio de protector general de indios en un virreinato maduro, que experimentaba el cese de la influencia criolla en la administración virreinal y en el que los intereses de las autoridades virreinales estaban más ligados a los de la Corona.

Los hombres que desempeñaron el cargo de protector general de indios tras la supresión del cargo de fiscal protector y la implementación de la Recopilación de 1680 y de los que disponemos de alguna información son: doctor don Gregorio de Rojas y Acebedo (1672), Lucas Segura (1673), capitán Francisco de Torres (1674), Alonso Hurtado de Mendoza (1678), Marcos López (1685), licenciado Pedro de Figueroa Dávila (1685) y Melchor Pacheco. Los casos en los que se vieron involucrados fueron generalmente litigios de tierras.

\section{El protector de indios en el siglo XVIII}

La Protectoría de Indios era ya una institución consolidada dentro del seno de la Audiencia. La Recopilación de Leyes de Indias de 1680 constituía a la planta de la Audiencia con ocho oidores, cuatro alcaldes del crimen, dos fiscales (uno en lo civil y otro en lo criminal) y un protector de indios. Aunque la institución original y formalmente había sido limitada al fuero civil, en la práctica, desde las primeras décadas del siglo XVII, atendía causas criminales, y en el siglo XVIII atendía de manera más evidente las causas criminales ante el contexto convulsionado de esa centuria.

En este siglo ocurrieron importantes cambios en el plano político virreinal. La élite criolla dominó el ambiente de la Audiencia la mayor parte del siglo, pero con la aplicación de las reformas borbónicas gradualmente perdieron protagonismo en la escena política virreinal hacia el último cuarto de siglo. El cargo de protector general de indios se mantuvo como un puesto importante o puesto trampolín para ascender a algún oficio de mayor jerarquía en la administración virreinal. Estuvo en manos de la élite indiana, que lo adquirió por nombramiento de la administración y comprándolo. El cargo por breves e intermitentes periodos tuvo la dignidad de fiscal a lo largo del siglo XVIII. 
Los inconvenientes de la venta de oficios públicos ${ }^{30}$ por parte de la Corona se hicieron más evidentes en esta centuria. En el caso de la Protectoría, sucedieron los más sonados casos de clientelismo y «corrupción» propiamente dichos. Presentamos a los protectores de los que disponemos información en este periodo en el cuadro ${ }^{31}$ subsiguiente:

\section{GRÁFICO 1}

\section{Protectores del siglo XVIII ${ }^{32}$}

\begin{tabular}{l} 
Isidro de Eceiza (c), protector general fiscal \\
\hline Tomás de Brun (e), protector fiscal general \\
\hline Francisco Ruiz de Berecero (c) \\
\hline José Martínez de España (e) \\
\hline Pedro José Rafael de Concha y Roldán (c), protector fiscal general \\
\hline Pedro de León y Escandón (e), protector general \\
\hline Pedro José Bravo de Lagunas (c), protector interino \\
\hline García José Lasso de la Vega e Hijar y Mendoza (c), protector general fiscal \\
\hline Tomás Azúa (¿?) \\
\hline Joaquín de Galdeano (e), protector fiscal \\
\hline Juan de Peralta y Sanabria (c) \\
\hline Felipe Santiago de Barrientos (c), protector general \\
\hline Manuel de Mansilla y Arias de Saavedra (c), protector general \\
\hline Cosme Antonio de Mier y Trespalacios (e) \\
\hline José Javier Leandro Baquijano y Carrillo (c), protector general interino de los \\
indios \\
\hline Gerónimo de Ruedas Morales (c)
\end{tabular}

Periodo

1708

1720

1723

1728

1730

1735

1736

1741

1749

1767

1771

\begin{tabular}{c}
\hline$?$ \\
\hline$? ?$ \\
\hline$?$ \\
\hline
\end{tabular}

1776,1781

Un caso emblemático es el del fiscal protector Pedro de la Concha y Roldán. José de Santiago-Concha, oidor de la Audiencia de Lima, compró para su hijo Pedro José Rafael de Concha y Roldán el cargo de protector

30 Una muy buena recopilación de artículos sobre este tema aparece en Ruiz Rivera, Julián y Sanz Tapia, Ángel (2007). La venta de cargos y el ejercicio del poder en Indias. León: Secretariado de Publicaciones de la Universidad de León.

31 Para la elaboración del cuadro tomamos los datos proporcionados en el estudio de Lohmann Villena, Guillermo (1974). Los ministros de la Audiencia de Lima en el reinado de los Borbones (1700-1821). Sevilla: Escuela de Estudios Hispano-Americanos de Sevilla.

32 Especificamos en cada caso el título de protector de cada uno de los magistrados nombrados. Entre las denominaciones tenemos: protector fiscal general y protector general fiscal. Señalamos también si ostentaron el cargo de manera interina. Añadimos una (c) para designar criollo y una (e) para español.

33Cuñado de Baquijano y Carrillo. 
de indios. Según Tord y Lazo, el oidor desembolsó la suma de veinte mil pesos (Tord y Lazo 1985 [1980]: 25), cifra bastante elevada. El caso llegó al Consejo de Indias y se le revocó del cargo. No obstante ello, Concha y Roldan se incorporaría a la administración pública como gobernador de Huancavelica y consejero del virrey. Sobre su padre han quedado testimoniados, a través de pasquines y sátiras de la época, serios cuestionamientos a su honradez como funcionario público (Lohmann 1972 y 1974). Por el caso de don Pedro de la Concha y Roldán podemos apreciar la nueva dinámica del poder en la Real Audiencia y la desnaturalización de la Protectoría de Indios ${ }^{34}$.

Al visitar el virreinato, Jorge Juan y Antonio de Ulloa se topan con la destitución de este protector. Sobre el respecto nos dicen:

Hallándonos en aquellas provincias fue privado del empleo de protector de los indios en la Audiencia de Lima D. José de la Concha, porque llegaron a noticias de su majestad y de sus ministros las quejas de lo mal que cumplía con la obligación de su ministerio. Es cierto que las quejas fueron justas, pero los que estábamos observando la conducta de otros que se hallaban en iguales empleos, y veíamos que no hacían lo mismo con ellos, siendo tan dignos de deposición, conocíamos hasta dónde llega el poder de las grandes distancias, pues por causalidad dejó correr aquellas quejas hasta llegar al trono, siendo general quedarse en su principio y desaparecer (Juan y Ulloa 1953: 237) [las cursivas son nuestras].

Al referirse Jorge Juan y Antonio de Ulloa a «iguales empleos», presumimos que se refieren a los procuradores y abogados de indios, quienes desempeñaban sus funciones en la Audiencia. También podrían referirse a los protectores de partido, aunque eso es algo más lejano, porque creemos que se refieren a igualdad de funciones en la Audiencia.

Son muy interesantes los datos que nos aportan en un contexto en que ya estaba en España Vicente de Mora Chimo, nombrado procurador general de los indios en 1721 y que tenía un pleito junto con su comunidad en la Audiencia contra el corregidor de Trujillo, Pedro Alzamora y Ursino, cuñado del oidor decano de la Audiencia Concha-Salvatierra y tío del fiscal protector general Pedro de la Concha y Roldán. Los apuntes de Sophie Mathis nos hacen pensar que Pedro de la Concha ocupó previamente el cargo de protector de naturales antes de comprarlo con la dignidad de fiscal protector. Mathis analiza la faceta de procurador general de los indios de Mora Chimo en la Corte, motivado por un litigio de 
apropiación de tierras iniciado por Alzamora bajo la protección de sus poderosos parientes. Aunque no precisa fecha, pone mucho énfasis en la vinculación familiar con Concha y Roldán de 1715 a 1721. Según Lohmann Villena, el hijo del oidor adquirió el cargo en 1730. Por el monto desembolsado, es poco factible que se hubiera adquirido el cargo si no ofrecía algún tipo de poder efectivo y utilidad práctica. El cargo de fiscal protector feneció de manera oficial en 1648. Sin embargo, durante el siglo XVIII tuvo una vida intermitente, pues el cargo de protector general apareció acompañado de la dignidad de fiscal hasta 1750.

\section{Nuevas legitimidades para los curacas}

Los indígenas formaron parte del sistema de la Protectoría, como lo ejemplifica el caso de don Lorenzo Paxiguana Alay Quiroz, cacique principal del pueblo de Yanque, nombrado protector de naturales de partido en la provincia de Collaguas, mediante una real provisión del marqués de Castelfuerte del 17 de junio de 1735 (León Fernández 2003). Se debe circunscribir este nombramiento a dos contextos específicos. En primer lugar, hubo un esfuerzo estatal por nombrar un mayor número de protectores «letrados», especialmente en los poblados sin audiencia (Cutter 1986: 50). En segundo lugar, cada vez era más generalizada la idea de que los indígenas eran los idóneos para responder a sus propias necesidades y que constituían un sector más leal a la Corona que los criollos (Ulloa 1953). La consolidación de los cabildos indígenas determinó una nueva fisonomía de relaciones político-administrativas, que dejaron de circunscribirse a la esfera del grupo étnico y el parentesco.

Los curacas o caciques indígenas eran hábiles litigantes. En el siglo XVIII hicieron sentir cada vez más su presencia como un grupo con intereses políticos bien definidos. Existía un clima positivo, al menos teórico e ilustrado, para que los naturales pudieran acceder a puestos administrativos como el de protector de partido, que era el caso de don Lorenzo Paxiguana, y el de procurador general de los indios en la Corte, que era el caso de Vicente de Mora Chimo. Los temas de conflicto fueron en esencia los mismos de siempre: el trabajo en las minas, la propiedad agrícola y la tributación. Este último fue el de mayor conflictividad, tanto así que desencadenó el gran movimiento insurreccional del siglo XVIII, que corroboró los temores de la Corona hacia los indígenas, y terminó por cortar drásticamente los privilegios y facultades de la élite indígena.

\section{Conclusiones}

La realidad material de un sistema basado en la explotación compulsiva de la mano de obra indígena hacía imposible la eficacia de una institución como la Protectoría de Indios. No obstante, la presencia de 
funcionarios y leyes protectoras permitieron a los indígenas poner cierto freno al atropello de sus derechos y obtener justicia en los tribunales.

Los intereses cambiantes de la Corona, desde el descubrimiento y conquista hasta el asentamiento definitivo de su dominio, requirieron que esta llevara a cabo una serie de alianzas y tolerancias para impedir la consolidación de grupos independientes de su poder. Desde esta perspectiva, la Protectoría permitió contribuir a dicho fin. Esto lo podemos apreciar al tomar en consideración los cambios en la calidad de los funcionarios designados para el cargo, las competencias otorgadas y las limitaciones contenidas expresadas en los diferentes cuerpos normativos, el constante roce jurisdiccional entre la Iglesia y las autoridades locales (corregidores).

La Protectoría, al tener bajo su competencia exclusiva la supervisión del buen trato a los indígenas, tenía la obligación tácita de velar y garantizar el usufructo equilibrado de la fuerza de trabajo indígena, verdadero motor de la economía. Esto suscitó que los protectores y la élite indígena entablaran alianzas y estrategias no solo con el objeto de poner freno al abuso cruel y real que ejercían los criollos y peninsulares dueños de los medios de producción (obrajes, estancias, latifundios, minas). Ello no estaba necesariamente en contradicción con la defensa de intereses personales ajenos a los procesos judiciales que planteaban los indígenas y que defendían apasionadamente protectores en su afán de hacerse de mayor prestigio y escalar en la carrera administrativa virreinal.

\section{Anexo}

\section{Evolución de la Protectoría de Indios ${ }^{35}$}

\section{Siglo XVI}

\section{El modelo lascasiano}

\section{6}

Nombramiento de Bartolomé de las Casas como protector de indios. Sus poderes y prerrogativas eran prácticamente ilimitados en lo referente a la vigilancia del tratamiento que recibían los indios. Debía viajar por todo el territorio de las Indias, e informar a los gobernadores y sus comisarios de cuanto estimase conveniente sobre los indígenas y la Corona. Cumplía una función de consejero real en asuntos indígenas, y enviaba información periódica sobre las acciones necesarias de tomar en Indias para salvaguardar la integridad de la población nativa. Convergían entre sus funciones las de ser procurador de los indígenas ante los tribunales, 
así como la de ser un inspector general del tratamiento que recibían. Contaba con amplia libertad de movimiento y capacidad de fiscalización y jurisdicción para juzgar la conducta de conquistadores y colonizadores.

\section{Los protectores obispos}

\section{0}

Se restringieron las prerrogativas de los protectores. Podían intervenir únicamente en casos menores y ejecutar penas pecuniarias inferiores a 50 pesos o penas de cárcel de menos de diez días.

1531-1554

Se invistió automáticamente a los obispos destacados a las diferentes diócesis como protectores de indios. Los obispos mantuvieron su labor de informantes reales y mantuvieron una fluida correspondencia con la Corona y el Consejo de Indias.

\section{Los fiscales de la Audiencia como protectores de indios}

\section{4}

La defensa de los indígenas pasó a recaer bajo responsabilidad de los fiscales de la Audiencia, para el caso peruano, de 1554 a 1557, según Solórzano.

\section{7}

Por una real cédula enviada a la Audiencia de Quito, se ordenaba desaparecer el cargo el 1 de febrero de 1567 (Encinas 1945: 333). Sin embargo, la cédula no fue acatada y el cargo siguió existiendo en el virreinato peruano.

\section{El protector general de indios toledano.}

\section{5}

El 10 de setiembre, en Arequipa, el virrey Francisco de Toledo dictaminó las ordenanzas sobre el defensor general de los indios. Con estas ordenanzas se institucionalizó la Protectoría como un cargo administrativo dependiente del virrey. Se le confirió una mayor organicidad, pues creó paralelamente cargos dependientes, como los protectores de partido, los procuradores de indios y los defensores de indios, para restringir el acceso de los litigios a la Real Audiencia de Lima. De esta manera, se intentó organizar el aparato judicial del virreinato, al convertir el cargo de protector en una suerte de ente catalizador y de filtro de las reclamaciones de los indígenas, en especial de los curacas y las comunidades indígenas. Veía en apelación las causas seguidas en los juzgados inferiores (corregimientos).

\section{2}

Desactivación de la Protectoría de Indios. Por real cédula del 27 de mayo de 1582, dirigida al presidente de la Real Audiencia de México, se 
ordenó la eliminación del oficio, aduciendo que el defensor de indios dañaba y perjudicaba notablemente a los naturales, contrariando la voluntad del rey. Se dispuso que en adelante fueran las audiencias las que tomaran el cuidado y amparo de los indios. La cédula era una circular, de modo que la abolición del cargo tuvo carácter general para todos los reinos del Imperio español.

\section{9}

Por real cédula del 10 de enero de 1589, dirigida al virrey Villar Don Pardo, se restituyó al defensor general y a los defensores de indios de partido, en vista que la eliminación del cargo había traído más inconvenientes que ventajas. Todo debía ceñirse a las ordenanzas sobre el oficio del virrey Francisco de Toledo.

1590

El virrey García de Mendoza, cuarto marqués de Cañete (gobierno de 1590-1596), sucesor de Villar Don Pardo, acusaba recibo de la cédula y procedió a su obediencia. El modelo de la Protectoría de Indios diseñado por el virrey Toledo fue el que rigió hasta 1643.

\section{Siglo XVII}

\section{El protector fiscal}

1614

Se discute por primera vez en el Consejo de Indias, a petición del monarca, la conveniencia o no de dotar al oficio de protector de indios de igual dignidad que un fiscal u oidor de la audiencia. El Consejo de Indias concluyó que convenía que el virrey nombrase a personas de máxima garantía, sin ánimo de lucro, pero sin garnacha.

\section{5}

Felipe III consulta al virrey Esquilache si convendría «proveer por plaza de asiento la Protectoría» en Lima, es decir, si convendría dotar al protector general de los indios de igual dignidad que un fiscal u oidor de la audiencia.

1640

El Consejo de Indias discutió la cuestión titulándola: Sobre los inconvenientes que tiene el beneficien los oficios de protectores de los indios y particularmente el que se les conceda que puedan traer garnacha. La Junta de Vestir la Casa propuso en 1640 que el nombramiento del protector lo hiciera directamente el rey y que tuviera algunas atribuciones. En concreto, que pudieran vestir la garnacha o toga, que fueran letrados, que contaran 
con asiento en las audiencias después de los fiscales y que, al mismo tiempo, fueran fiscales de la bula de la cruzada.

1643-1648

A partir de 1643 se instituyó en el virreinato peruano, en la Audiencia de Lima, el cargo de fiscal protector de los indios, con carácter autónomo y como magistrado independiente. Podía vestir toga como los demás integrantes de dicho tribunal. Su misión consistió en actuar de defensor nato de los indígenas de todo el distrito de la audiencia, no solo en calidad de procurador de sus pleitos sustanciados ante ella, sino, sobre todo, amparándolos en caso de queja contra sus corregidores y acogiendo sus demandas para reducción del monto de los tributos. En resolución, tendiendo su manto protector sobre los nativos, para evitar toda ofensa o agravio que se pretendiere inferirles.

\section{6}

Por real cédula del 30 de junio se ordenó que en los casos en que los españoles hubieran adquirido tierras de indios de modo ilícito, los fiscales protectores debían pedir en nombre de ellos la nulidad de dichas adquisiciones (Suárez 1995: 302).

\section{8-1686}

Durante este interregno de tiempo se regresó al sistema de protectoría toledano, mientras gradualmente se desactivaba el cargo de fiscal protector en los virreinatos americanos.

\section{La Recopilación de Leyes de Indias}

\section{0}

Promulgación de la Recopilación de Leyes de Indias. El título VI de su libro VI señala todas las funciones, instrucciones y actividades procesales que de ahí en adelante debían regir las competencias y funciones de los protectores de indios. La Recopilación aportó tres elementos importantes en la evolución de la Protectoría. Señaló enfáticamente la dependencia del protector general de indios a la administración virreinal (Ley I, II, VI, XII), se ocupó de las relaciones de los protectores con las autoridades superiores del virreinato (Ley X, XIV) y, frente a la dependencia del cargo a las autoridades virreinales, trató de darle cierta estabilidad al cargo exigiendo que los protectores no fuesen destituidos sin causa legítima; además, se exhortó a la Audiencia a pronunciarse sobre la legitimidad y certeza de las causas por las que se destituía al protector (Ley V). En lo referente a la acción legal de los protectores en defensa de los indígenas en los tribunales, se mantuvo, en esencia, lo estipulado en las ordenanzas de Toledo. 


\section{4}

Los primeros ejemplares de la flamante legislación se embarcaron en Sevilla en setiembre hacia los reyes.

\section{5}

Llegada a Lima de la Recopilación, según carta de Pedro Frasso al virrey el 30 de abril de 1686.

\section{6-1690}

La aplicación de la legislación de la Recopilación fue intermitente y dificultosa. Hasta 1686 aún se sometía a evaluación la conveniencia de su aplicación para la realidad del virreinato peruano.

\section{Siglo XVIII}

\section{Cargo institucionalizado en la Real Audiencia}

\section{0}

La Recopilación de Leyes de Indias de 1680 constituía a la planta de la Audiencia con ocho oidores, cuatro alcaldes del crimen, dos fiscales (uno en lo civil y otro en lo criminal) y un protector de indios. La Protectoría como cargo afincado en la Real Audiencia se asemejará en funciones al fiscal del crimen. Durante todo el siglo el cargo fue un requisito para acceder a oficios de mayor jerarquía en la administración colonial, pues criollos y peninsulares pasarán por este cargo antes de ser destacados como fiscales u oidores en la Audiencia de Lima o en otra audiencia del Imperio español en América.

1700-1770

Intermitentemente el cargo gozó de la dignidad de fiscal. Esta prerrogativa se concedía cuando el cargo era adquirido onerosamente.

1750-1780

Con posteridad a 1750 se hizo más común el destacamiento de los funcionarios de la audiencia interinamente en el cargo. 


\section{REFERENCIAS BIBLIOGRÁFICAS}

ACEBEDO, Edberto Óscar (1991). «El protector de Indios en el Alto Perú (hacia fines del régimen español)». En IX Congreso del Instituto Internacional del Derecho Indiano. Madrid: Editorial de la Universidad Complutense.

ÁLVAREZ PERCA, Guillermo (2010). «Fray Jerónimo de Loayza, primer arzobispo de Lima». En Revista de Historia Eclesiástica, nro. 12, pp. 7-28.

ANDRIEN, Kenneth J. (2011). Crisis y decadencia. El Virreinato del Perú en el siglo XVII. Lima: Instituto de Estudios Peruanos.

AMADORI, Arrigo (2009). «Que se de diferente modo al gobierno de las indias, que se van perdiendo muy aprisa. Arbitrismo y administración a principios del siglo XVII». En Anuario de Estudios Americanos, nro. 66, vol. 2, pp. 147-169.

BARRIGA, P. Víctor M. (1939). Documentos para la historia de Arequipa. 1534-1558. Documentos inéditos de los Archivos de Arequipa. Arequipa: Editorial La Colmena

BAYLE, Constantino (1945). El protector de indios. Sevilla: Consejo Superior de Investigaciones Científicas.

BENITO RODRÍGUEZ, José Antonio (2007). «P. Vicente Valverde, pionero de la evangelización del Perú». En Revista Peruana de Historia Eclesiástica, nro 10.

BURKHOLDER, Mark A. y D. S. CHANDLER (1984 [1977]). De la impotencia a la autoridad. La Corona española y las Audiencias en América 1687-1808. México D. F.: Fondo de Cultura Económica.

CHASSIN, Joëlle (1992). «Protecteur d'Indiens contre Vice-Roi: la lutte de Miguel de Eyzaguirre pour l'abolition du tribut au Pérou». En Cahiers des Amériques Latines, nro. 13, pp. 61-74

CUENA BOY, Francisco José (1998a). «El defensor civitatis y el protector de indios: breve ilustración en paralelo». En lus Fugit. Revista Interdisciplinar de Estudios Histórico-Jurídicos, nro. 7, pp. 179-196.

(1998b). «El protector de indios en clave romanística: una propuesta del siglo XVII». En César Rascón García (coordinador). III Congreso lberoamericano de Derecho Romano. León: Asociación Iberoamericana de Derecho Romano.

(1998c). «Utilización pragmática del derecho romano en dos memoriales indianos del siglo XVII sobre el protector de indios». En lus Fugit. Revista de Estudios Históricos-Jurídicos, nro. 20.

CUNILL, Caroline (2011). «El indio miserable: nacimiento de la teoría legal en la América colonial del siglo XVI». En Cuadernos interCAmbio, año 8, nro. 9, pp. 229-248. 
GARCÍA HERNÁN, Enrique (2007). Consejero de ambos mundos. Vida y obra de Juan de Solórzano y Pereira (1575-1655). Madrid: Fundación Mapfre.

HIDALGO NUCHERA, Patricio (1998). «Origen y desactivación de la Protectoría de Indios en la Presidencia-Gobernación de las Islas Filipinas». En Revista Española del Pacífico, nro. 8.

HONORES, Renzo (1993). Litigiosidad indígena ante la Real Audiencia, 1552-1598. Tesis para optar por el título de abogado. Lima: Pontificia Universidad Católica de Perú.

(2007). Una sociedad legalista: Abogados, procuradores de causa y la creación de una cultura legal colonial en Lima y Potosí, 15401670. Tesis. Florida: Department of History, International University.

JUAN, Jorge y ULLOA, Antonio de (1953). Noticias secretas de América. Buenos Aires: Mar Océano.

KELLER, Suzanne (1971). Más allá de la clase dirigente. Élites estratégicas en la sociedad moderna. Madrid:Tecnos.

KONETZKE, Richard (1953-1958). Colección de documentos para la historia de la formación social de Hispanoamérica. 1493-1810. Madrid: Consejo Superior de Investigaciones Científicas.

LAZO GARCÍA, Carlos y TORD NICOLINI, Javier (2007). Obras escogidas de Carlos Lazo García. Historia de la economía colonial. Hacienda, comercio, fiscalidad y luchas sociales. Lima: Fondo Editorial del Pedagógico San Marcos.

LEÓN FERNÁNDEZ, Dino (2003a). «Un manuscrito sobre el protector de los naturales en la provincia de Collaguas. Siglo XVIIl». En Revista de Investigaciones Históricas Uku Pacha, año 4, nro. 5, pp. 91-107.

LEURIDAN HUYS, Johan (1997). José de Acosta y el origen de la idea de misión. Perú, siglo XVI. Cusco: Centro de Estudios Regionales Andinos Bartolomé de las Casas y Universidad de San Martín de Porres.

LOHMANN VILLENA, Guillermo (1972). «La poesía satírico-política durante el virreinato». En Boletín de la Academia Peruana de la Lengua, nro. 7, pp. 37-108.

(1999 [1948]). Las minas de Huancavelica en los siglos XVI y XVII. Lima: Fondo Editorial de la Pontificia Universidad Católica del Perú.

(2001 [1957]). El corregidor de indios en el Perú bajo los Austrias. Lima: Fondo Editorial de la Pontificia Universidad Católica del Perú.

LONGO, Carlo (1996). «Juan Solano, O. P. (¿1505?-1580), segundo obispo de Cusco, y la fundación del Colegium S. Thomae de Urbe». En Revista Andina, nro. 26, año 14, pp. 509-524. 
MACIEREWICZ, Antoni (1989). «Los primeros programas coloniales: la Iglesia frente a la conquista del Perú (1529-1541). En Iglesia, religión y sociedad en la historia latinoamericana. Szeged: Jate Kiadó.

MARTIRÉ Eduardo (s/f). «El dominio de las Indias: la tolerancia como regla de gobierno de la monarquía». Consultado el 7 de diciembre de 2011 en http://www.ancmyp.org.ar/user/files/martire.pdf

MORA MÉRIDA, José Luis (1981). «Fray Juan Solano, obispo del Cusco». En Primeras Jornadas de Andalucía y América: La Rábida, vol. 2, pp. 79-94.

MATHIS, Sophie (2008). «Vicente Mora Chimo, de indio principal a procurador general de indios del Perú: cambio de legitimidad del poder autóctono a principios del siglo XVII». En Bulletin de I'Institut Français d'Études Andines, nro. 37, vol. 1, pp. 199-215.

MORALES PADRÓN, Francisco (1979). Teoría y leyes de la Conquista. Madrid: Ediciones Cultura Hispánica del Comité Iberoamericano de Cooperación.

MOREYRA PAZ SOLDÁN, Manuel (1994). «El doctor Alberto de Acuña, oidor en Lima, nominado presidente en Guadalajara». En Estudios históricos. Oidores y virreyes. Lima: Fondo Editorial de la Pontificia Universidad Católica del Perú.

NOVOA, Mauricio (2003). Defensoría del pueblo: Aproximaciones a una institución constitucional. Lima: Universidad de Lima.

(2006). «La práctica judicial y su influencia en Solórzano: la Audiencia de Lima y los privilegios de indios a inicios del siglo XVIl». En Juan de Solórzano y Pereira. Pensar la colonia desde la colonia. Bogotá: Universidad de los Andes.

OLMEDO JIMÉNEZ, Manuel (1990). Fray Jerónimo de Loaysa, pacificador de los españoles y protector de los indios. Granada: Universidad de Granada y Editorial San Esteban.

PEASE, Franklin (1990). «¿Por qué los andinos son acusados de litigiosos?». En Los derechos culturales. Lima: Fondo Editorial de la Pontificia Universidad Católica del Perú.

RUIGÓMEZ GÓMEZ, Carmen (1988). Una política indigenista de los Habsburgo: el protector de indios en el Perú. Madrid: Superior de Investigaciones Científicas.

SUÁREZ, Santiago-Gerardo (1995). Los fiscales indianos. Origen y evolución del Ministerio Público. Caracas: Biblioteca de la Academia Nacional de la Historia.

TALAVERA VELEZMORO, Juan Carlos (2009). «Indumentaria académica sanmarquina: una introducción histórica sobre el antecedente y evolución del traje académico protocolar en el Perú». Ponencia en el XI Coloquio de la Historia de Lima. Universidad Nacional Mayor de San Marcos. 
VARÓN GABAI, Rafael (1997). La ilusión del poder. Apogeo y decadencia de los Pizarro en la conquista del Perú. Lima: Instituto de Estudio Peruanos e Instituto Francés de Estudios Andinos.

SARAVIA SALAZAR, Javier Iván (2012a). Los miserables y el protector. Evolución de la protectoria de indios en el virreinato peruano. Siglos XVI-XVIII. Lima: Universidad Nacional Mayor de San Marcos.

(2012b). «El fiscal protector de indios en la Audiencia de Lima, siglo XVII. Espacios de poder y arbitrismo». En Actas del Quinto Congreso Nacional de Historia. Lima: Universidad Nacional Mayor de San Marcos. 